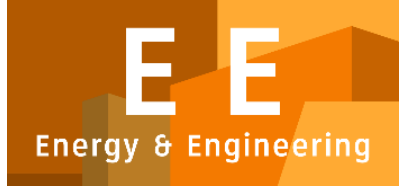

PAPER - OPEN ACCESS

\title{
Penerapan Metode Fuzzy Analytical Hierarchy Process dan SLP dalam Rangka Perancangan Ulang Tataletak Fasilitas Produksi Bata Ringan di Pt. PQR
}

$\begin{array}{ll}\text { Author } & : \text { Ukurta Tarigan } \\ \text { DOI } & : 10.32734 / \text { ee.v1i1.116 } \\ \text { ISSN } & : 2654-7031 \\ \text { E-ISSN } & : 2654-704 X\end{array}$

Volume 1 Issue 1 - 2018 TALENTA Conference Series: Energy and Engineering

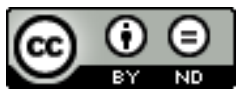

This work is licensed under a Creative Commons Attribution-NoDerivatives 4.0 International License.

Published under licence by TALENTA Publisher, Universitas Sumatera Utara
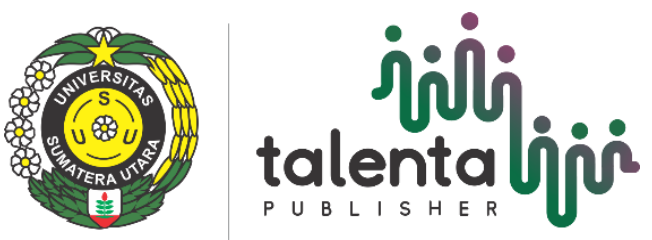


\title{
Penerapan Metode Fuzzy Analytical Hierarchy Process dan SLP dalam Rangka Perancangan Ulang Tataletak Fasilitas Produksi Bata Ringan di Pt. PQR
}

\author{
Ukurta Tarigan $^{\mathrm{a} *}$, Erwin Sitorus $^{\mathrm{a}}$, Veronica $^{\mathrm{a}}$ \\ Departemen Teknik Industri, FakultasTeknik, Universitas Sumatera Utara, Indonesia \\ ukurta.tarigan@yahoo.com,erwin_sitorus@yahoo.com, veronicachen344@gmail.com
}

\begin{abstract}
Abstrak
PT. PQR merupakan perusahaan yang bergerak dalam produksi bata ringan. Bata ringan diproduksi menggunakan sistem Autoclaved Aerated Concrete (AAC). Dari hasil pengamatan di perusahaan, produk bata ringan sering mengalami kerusakaan karena jatuh dari pallet saat dipindahkan menggunakan hand lift. Hal ini disebabkan oleh jauhnya jarak perpindahan antara lantai produksi dan gudang produk, sehingga operator kesulitan dalam proses pemindahan. Tujuan dari penelitian ini adalah untuk merancang ulang tata letak fasilitas dengan menggunakan pendekatan metode Fuzzy Analytical Hierarchy Process (Fuzzy AHP) disertai dengan metode Systematic Layout Planning (SLP) untuk mendapatkan rancangan yang efisien. Hasil pembobotan matriks berpasangan menunjukkan tenaga kerja adalah variabel yang memiliki bobot kriteria tertinggi sebesar 0,2735 . Setelah dilakukan analisis didapatkan bahwa kedekatan antar departemen sangat dipengaruhi oleh perpindahan tenaga kerja (operator) antar departemen. Dari hasil analisis, dirancang activity relationship chart (ARC) untuk mendapatkan kedekatan antar departemen, kemudian dirancang layout baru berdasarkan pertimbangan luas masing-masing departemen. Hasil rancangan ini dibandingkan dengan rancangan awal, sehingga diperoleh pengurangan jarak sebesar 165,01 m.
\end{abstract}

Kata Kunci: Perancangan Tata Letak Fasilitas; Fuzzy Analytic Hierarchy Process (FAHP); Systematic Layout Planning (SLP); Activity Relationship Chart (ARC);

\section{Pendahuluan}

Permasalahantataletakterutamasekalimenyangkutminimasidaripenanganan material, memanfaatkan area yang ada, memberi kenyamanan bagi tenaga kerja, memudahkan proses manufaktur dan sebagainya. PT.PQR merupakan perusahaan manufaktur yang bergerakdi bidang produksi batu bata ringan. Kondisi tata letak fasilitas PT. PQR yang tidak teratur menyebabkan proses produksi tidak dapat berjalan dengan efektif. Beberapa departemen memiliki jarak yang jauh apabila dianalisis menurut jarak perpindahan. Jauhnya jarak perpindahan material dari beberapa departemen ke departemen yang lain ditunjukkan pada Tabel 1. 
Tabel 1. Jarak Perpindahan Bahan dari Beberapa Departemen

\begin{tabular}{ll}
\hline Departemen & Jarakperpindahan \\
\hline Timbangan - BagianPenerimaandanPengiriman & $4,8 \mathrm{~m}$ \\
Timbangan - GudangBahan Baku & $7,9 \mathrm{~m}$ \\
GudangBahan Baku - Produksi & $8,2 \mathrm{~m}$ \\
Produksi - GudangProduk & $16,7 \mathrm{~m}$ \\
GudangProduk - BagianPenerimaandanPengiriman & $18,8 \mathrm{~m}$ \\
GudangProduk - Timbangan & $21,2 \mathrm{~m}$
\end{tabular}

Tabel di atas menunjukkan jauhnya perpindahan material antara satu departemen dengan departemen lainnya.Tabel berikutmenunjukkan ketidakteraturan layout awal dan aliran bahan pada PT. PQR, dapat dilihat pada Gambar 1
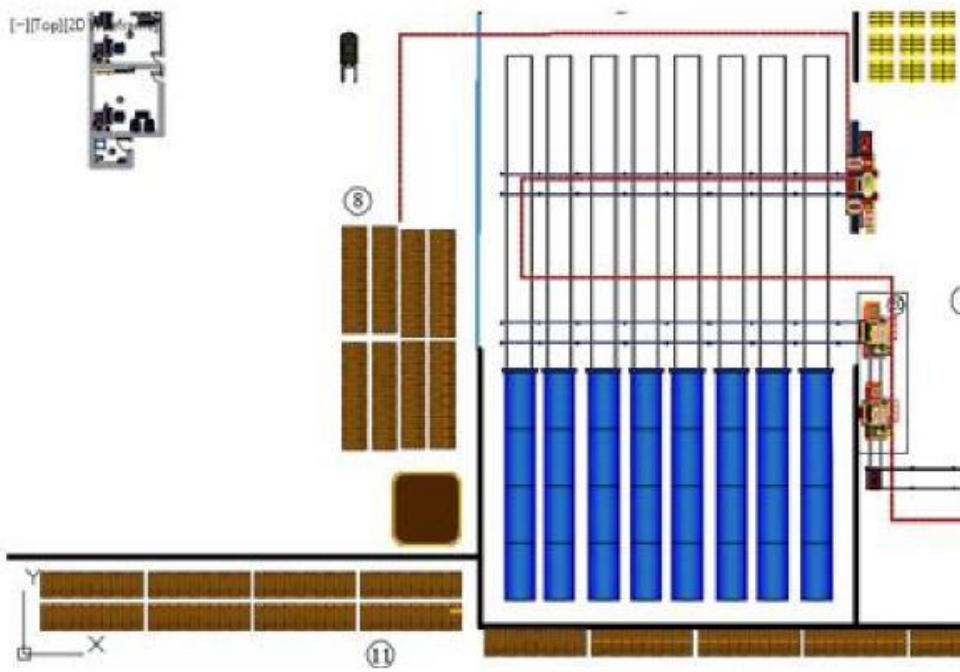

(9)

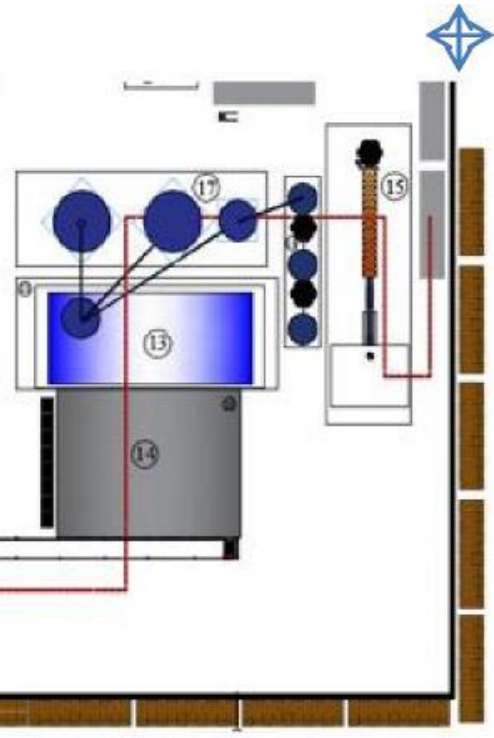

Keterangan Gambar :

Aliran Bahan

Gambar 1. Layout Awal PT. PQR

Dari Gambar 1 dapat dilihat bahwa pola aliran bahan pada PT. PQR berbentuk tidak berarutan. Berdasarkan permasalahan yang terjadi pada PT. PQR peneliti melakukan perancangan ulang tata letak fasilitas dengan metode Fuzzy Analytical Heirarchy Process (FAHP) untuk mendapatkan rancangan alternatif yang baik.

Penelitian tentang perancangan tata letak fasilitas dengan menggunakan metode pendekatan fuzzy AHP untuk mengambil keputusan dalam merancang tata letak (F. Dweiri, 2007). Dalam penelitiannya, evaluasi terhadap rancangan tata letak dilakukan berdasarkan beberapa kriteria seperti hubungan antar departemen, hubungan aliran (aliran bahan, tenaga kerja, peralatan, informasi dan uang), hubungan pengawasan (pengawasan inventori, bahan dan lantai produksi), hubungan lingkungan (keamanan, suhu, kebisingan dan debu) serta hubungan proses (pelayanan khusus). AHP digunakan sebagai kerangka umum formulasi sistem evaluasi yang seimbang dengan kriteria berbeda. Pendekatan fuzzy untuk masalah tata letak fasilitas melibatkan identifikasi variabel linguistik yang menggambarkan faktor kuantitatif dan kualitatif yang mempengaruhi hubungan fasilitas, pemilihan dan penentuan nilai-nilaidanfungsi keanggotaan untuk variabel linguistic dan pengembangan prosedur heuristic untuk seleksi dan penempatan fasilitas dan evaluasi tata letak. 


\section{Metode Penelitian}

\subsection{Subjek dan Objek Penelitian}

Penelitian ini termasuk dalam penelitian action research yaitu suatu penelitian yang dilakukan untuk mendapatkan temuan praktis untuk keperluan pengambilan keputusan operasional yang mampu diaplikasikan pada perusahaan (Sukaria Sinulingga, 2013). Objek penelitian yang diteliti oleh peneliti adalah hubungan antar departemen yang ada di PT. PQR serta variabel aliran bahan, informasi, peralatan dan tenaga kerja).

\subsection{Prosedur Pelaksanaan Penelitian}

Prosedur pelaksanaan penelitian terdiri dari beberapa tahap yaitu :

1. Studi pendahuluan

2. Identifikasi masalah awal

3. Studi literatur

4. Pengumpulan data (data matriks perbandingan berpasangan dan frekuensi aliran)

5. Pengolahan data (penerapan metode AHP dan metode Fuzzy)

6. Analisis pemecahan masalah

7. Kesimpulan dan saran

\subsection{Ukuran Sampel dan Teknik Sampling}

Teknik sampling yang digunakan pada penelitian ini adalah purposive sampling dikarenakan jumlah responden yang terbatas dan peneliti ingin mendapatkan informasi dari kelompok tertentu yaitu kepala bagian yang memahami masalah tata letak. Berikut sampel yang digunakan dapat dilihat pada Tabel 2.

Tabel 2. Sampel PT. PQR

\begin{tabular}{lll}
\hline No & Jabatan & Jumlah \\
\hline 1 & Kepala bagian produksi & 1 \\
2 & Kepala seksi produksi & 1 \\
3 & Kepala seksi gudang & 1 \\
4 & Kepala seksi teknik & 1 \\
5 & Staff perbengkelan & 1 \\
\hline Total & & 5 \\
\hline
\end{tabular}

\section{Hasil dan Pembahasan}

\subsection{Pembuatan Struktur Hierarki Pemilihan Variabel Performansi}

Struktur hierarki bertujuan untuk mengetahui alternative variabel performansi tata letak yang akan digunakan. Kriteria-kriteria ini disusun ke dalam bentuk hierarki seperti yang dapat dilihat pada Gambar2. 


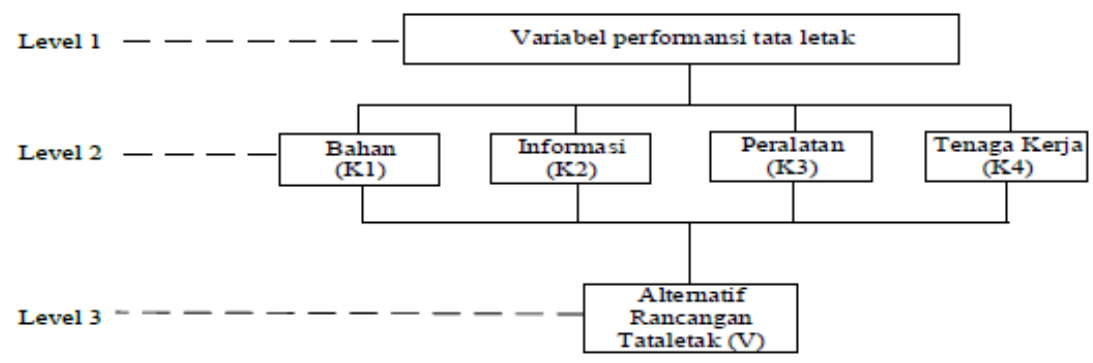

(a)

Gambar 2. Struktur Hierarki Pemilihan Variabel Performansi Tata Letak

\subsection{Matriks Perbandingan Berpasangan (Pairwise Comparison)}

Matrik sini bertujuan untuk melihat perbandingan setiap kriteria dan tingkat kepentingan dari kriteria yang satu dengan kriteria yang lainnya. Berikut data pengumpulan hasil kuesioner responden 1 dapat dilihat pada Tabel 3.

Tabel 3. Matriks Perbandingan Berpasangan Variabel Performansi Tata Letak Responden 1

\begin{tabular}{lllll}
\hline Kriteria & $\mathrm{K} 1$ & $\mathrm{~K} 2$ & $\mathrm{~K} 3$ & $\mathrm{~K} 4$ \\
\hline K1 & 1 & $1 / 4$ & 3 & 3 \\
$\mathrm{~K} 2$ & 4 & 1 & $1 / 3$ & $1 / 2$ \\
$\mathrm{~K} 3$ & $1 / 3$ & 3 & 1 & 3 \\
$\mathrm{~K} 4$ & $1 / 3$ & 2 & $1 / 3$ & 1 \\
\hline
\end{tabular}

\subsection{PerhitunganRasio Konsistensi dan Konsistensi Matriks}

Perhitungan rasio konsistensi dan konsistensi matriks menggunakan rumus-rumus berikut ini (Saaty:1994):

1. Perhitungan Rasio Konsistensi

$=($ Matriks Perhitungan Rata-Rata Pembobotan) $\mathrm{x}$ (Vektor Bobot tiap baris)

2. Perhitungan Konsistensi Vektor

$=($ Rasio Konsistensi / Bobot Parsial tiap baris $)$

3. Rata-rata Entri (Zmaks)

$$
Z_{\text {maks }}=\frac{\sum_{i=1}^{n} \text { KonsistensiVektor }}{n}
$$

4. Consistency Index (CI)

$$
C I=\frac{Z_{\text {maks }}-n}{n-1}
$$

5. Consistency Ratio (CR)

$$
C R=\frac{C I}{\text { Random Consistency Index }}
$$


Jawaban responden dianggap konsisten bila nilai $C R<0,1$. Dari hasil perhitungan diperoleh $\mathrm{CR}=-0,2371$, nilai $\mathrm{CR}<0,1$ maka jawaban yang diberikan oleh responden konsisten. 3.4.

\subsection{PerhitunganBobotLokal Fuzzy Level 2 (Kriteria)Matriks}

Perhitungan bobot lokal Fuzzy menggunakan Chang's Analysis Extent untuk level 2 yaitu sebagai berikut. 1. Perhitungan fuzzy synthetic extent value dengan rumus:

$$
\begin{aligned}
& S_{i}=\sum_{j=1}^{m} M_{g i}^{j} \otimes\left[\sum_{i=1}^{n} \sum_{j=1}^{m} M_{g i}^{j}\right]^{-1} \\
& K 1=\sum_{j=1}^{6} M_{g i}^{j} \otimes\left[\sum_{i=1}^{6} \sum_{j=1}^{6} M_{g i}^{j}\right]^{-1}
\end{aligned}
$$

2. Perhitungan degree of possibility menurut aturan:

$$
\mathrm{V}\left(\mathrm{M}_{2} \geq \mathrm{M}_{1}\right)
$$

$$
\left\{\begin{array}{c}
1, \text { if } m_{2} \geq m_{1} \\
0, \text { if } l_{1} \geq u_{2} \\
\frac{l_{1}-u_{2}}{\left(m_{2}-u_{2}\right)-\left(m_{1}-l_{1}\right)} \text { otherwise }
\end{array}\right.
$$

Contoh perhitungan degree of possibility:

$\mathrm{V}(\mathrm{K} 1>\mathrm{K} 2)$

3. Penentuan vektor terbobot $\left(\mathrm{W}^{\bullet}\right)$ :

$V(K 1 \geq K 2 ; K 3 ; K 4)$

4. Normlisasi vektor terbobot (W) :

$$
W K 1=0,8505 / 0,8505+0,9569+0,8495+1=0,2326
$$

Tabel 4. Normalisasi Vektor Terbobot Level 2 (Kriteria)

\begin{tabular}{ll}
\hline Kriteria & W \\
\hline K1 & 0,2326 \\
K2 & 0,2617 \\
K3 & 0,2323 \\
K4 & 0,2735 \\
\hline
\end{tabular}

Dari tabel di atas, dapat dilihat K4 (variabel tenaga kerja) memiliki bobot tertinggi sebesar 0,2735.

\subsection{Penyusunan Aturan IF-THEN}

Metode ini ditentukan dengan melihat frekuensi dari masing-masing variabel lalu menetapkan variabel linguistic untuk menyatakan tingkat kedekatan departemen berdasarkan bobot variabel linguistic masing-masing variabel, seperti yang ditampilkan olehTabel 5 . 
Tabel 5. Aturan IF-THEN untukVariabel Aliran Bahan, Informasi, Peralatan dan Tenaga Kerja

\begin{tabular}{llllll}
\hline \multirow{2}{*}{ Aliran Bahan } & \multicolumn{5}{c}{ Bobot Variabel } \\
\cline { 2 - 6 } & Sangat Rendah & Rendah & Sedang & Tinggi & Sangat Tinggi \\
\hline Sangat Rendah & U & O & O & O & O \\
Rendah & O & O & I & I & I \\
Sedang & O & O & I & I & E \\
Tinggi & O & I & I & E & E \\
Sangat Tinggi & O & I & E & E & A \\
\hline
\end{tabular}

\subsection{Proses Defuzzifikasi (Defuzzification Interface)}

Pada proses ini tingkat kedekatan antar departemen yang tadinya bersifat fuzzy, diubah kebentuk crisp yang nantinya menjadi input nilai pada Crisp Activity Relationship Chart dengan menggunakan rumus Center of Area (COA). Berikut hasil seluruh perhitungan Crisp Activity Relationship Chart (CARC) seluruh departemen, dapat dilihat pada Tabel 6 .

Tabel 6.Crisp Activity Relationship Chart

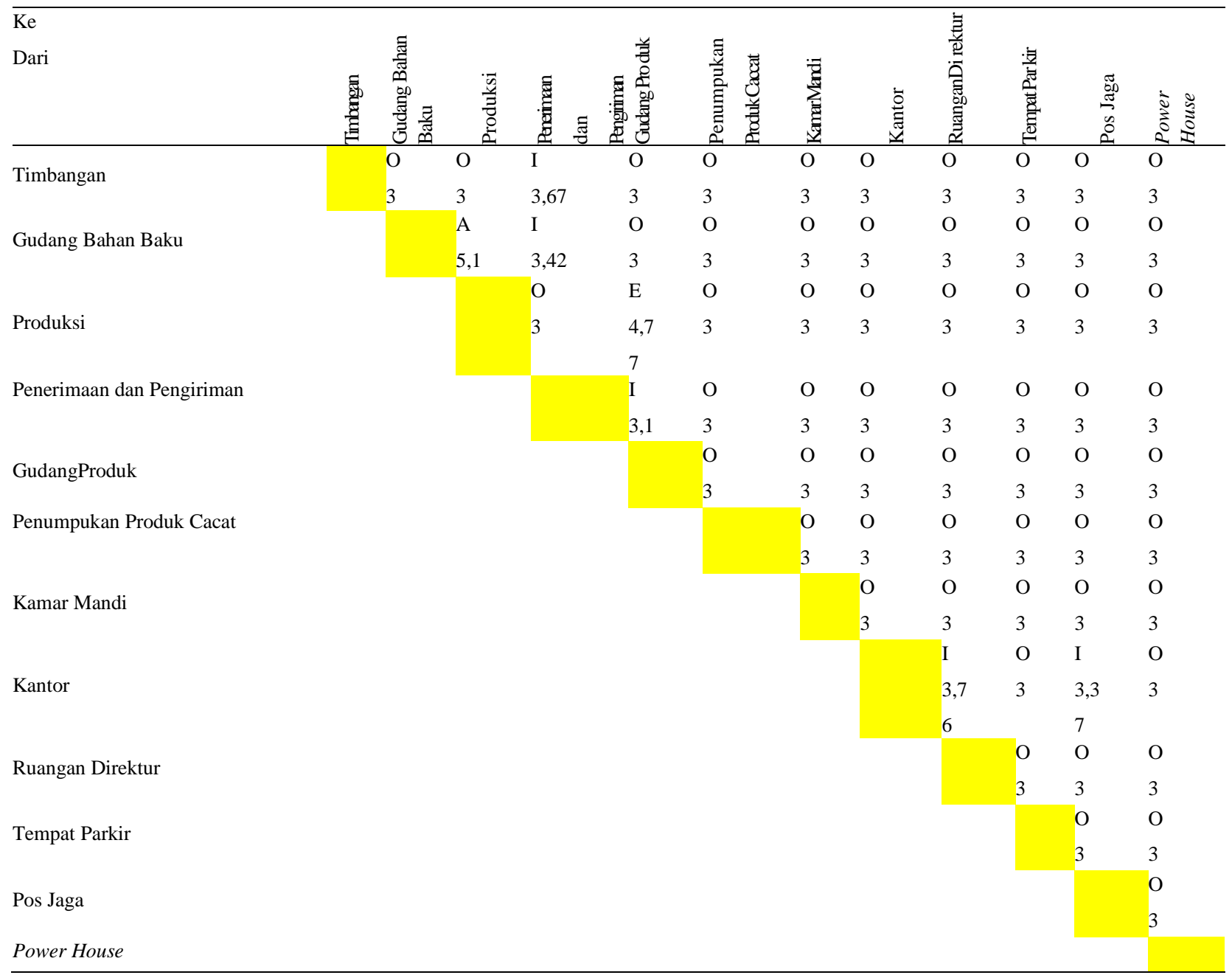


Dari hasil CARC, digambarkanActivity Relationship Chart (ARC) yang dapat dilihat pada Gambar 3, yang kemudian diteruskan penyusunan layout dengan metode Systematic Layout Planning sertafinal layout dengan pertimbangan luas masing-masing departemen, yang dapat dilihat pada Gambar 4.

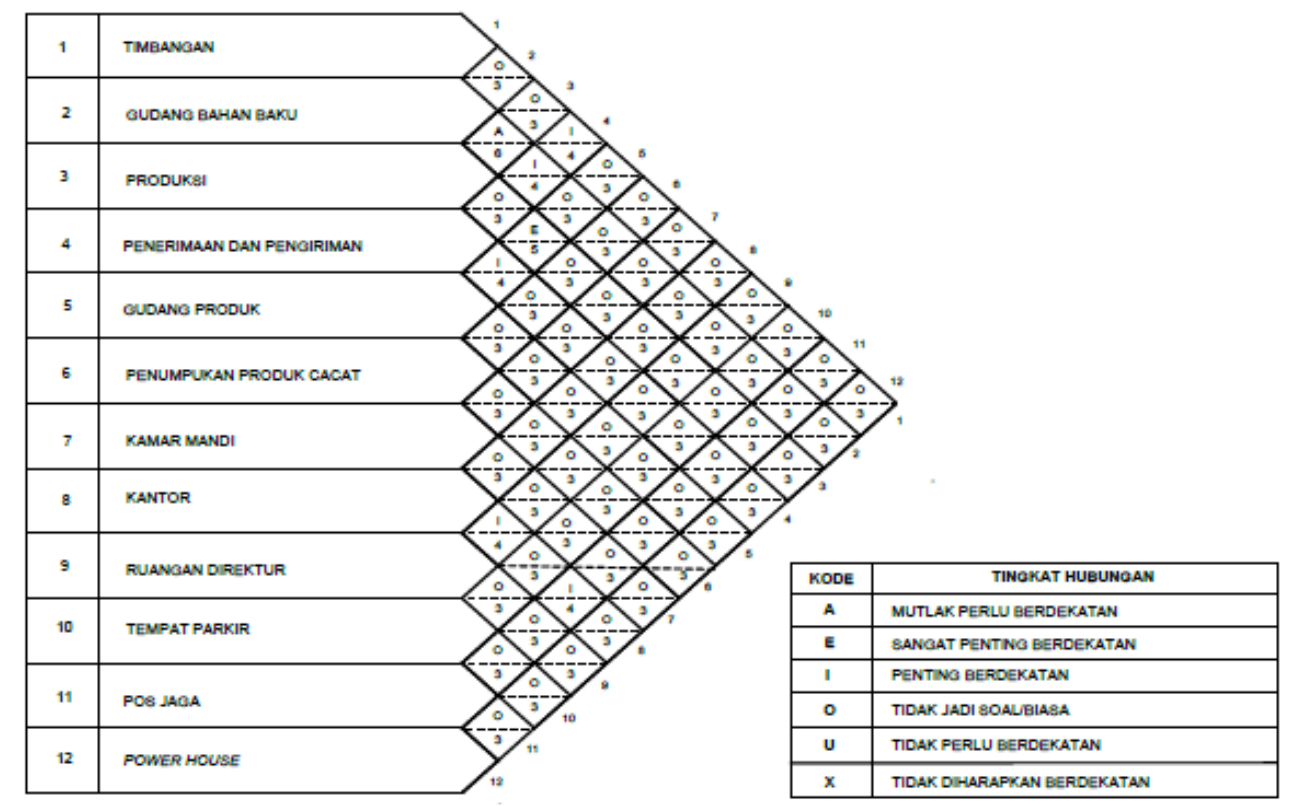

Gambar 3. Activity Relationship Chart

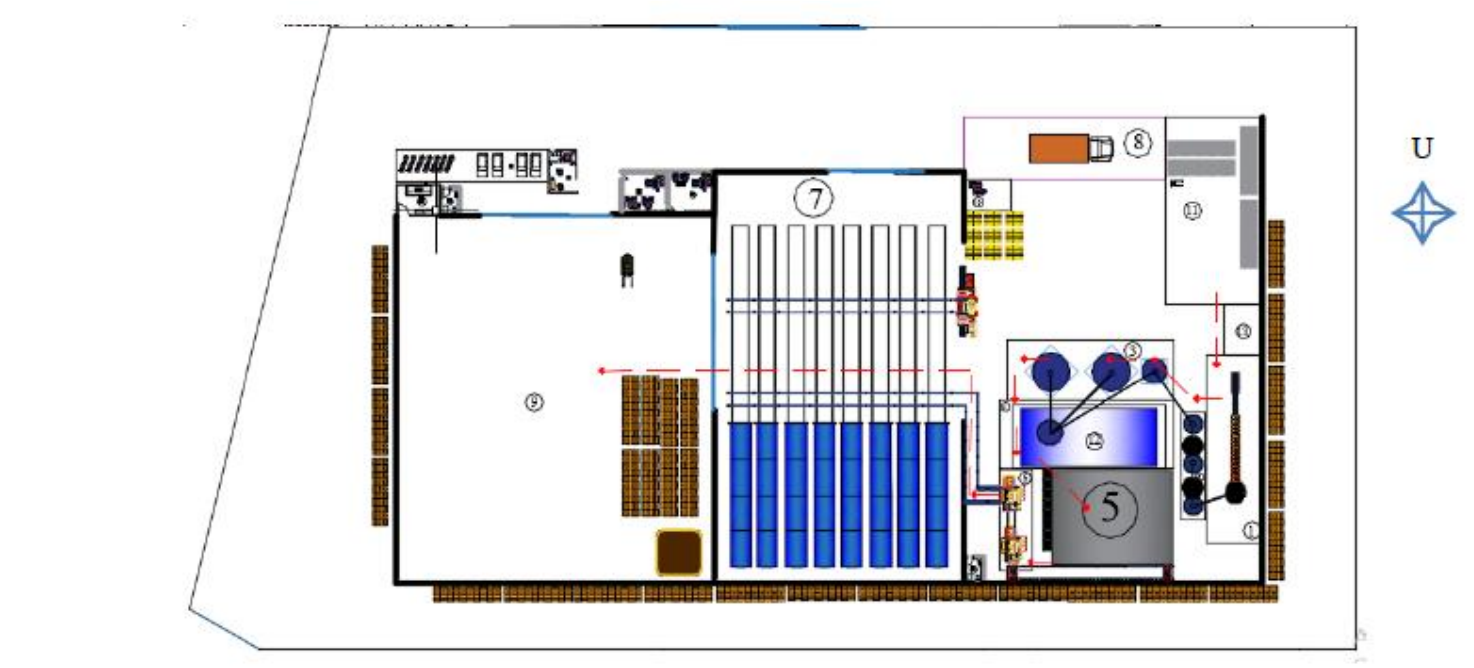

Keterangan Gambar :

Aliran Bahan

Gambar 4. Final Layout

\section{Kesimpulan}

Perancangan ulang tata letak fasilitas pada PT. PQR menggunakan 4 variabel yaitu, aliran bahan, informasi, peralatan dan tenaga kerja. Variabel yang paling mempengaruhi tata letak adalah variabel aliran tenaga kerja, dimana 
variabel ini memiliki bobot sebesar 0,2919 dengan fungsi keanggotaan $(\mu)$ sebesar 1.Untuk tingkat kedekatan paling tinggi adalah departemen gudang bahan baku dengan produksi memiliki rating A dengan nilai derajat keanggotaan sebesar 5,1, dimana kedua departemen ini yang diubah jaraknya dari layout awal. Selisih jarak perpindahan antara layout awal dengan layout usulan adalah165,01 meter.

\section{Referensi}

[1] Apple, James M. 1990. Tata letak Pabrik dan Pemindahan Bahan. Edisi Ketiga. Bandung: Penerbit ITB.

[2] Azadeh.A, dkk. 2015. Optimization of facility layout design with ambiguity by an efficient fuzzy multivariate approach. International Journal Advanced Manufacture Technology.

[3] Badiru, Adedeji.B. 2007. FLEXPERT: Facility Layout Expert System Using Fuzzy Linguistic Relationship Codes. University of Oklahoma.

[4] Chang, Da Yong. 1996. Application of The Extent Analysis Method on Fuzzy AHP. European Journal of Operation Research.

[5] Che, Jui Tu. 2015. Fuzzy AHP and Fuzzy TOPSIS Integrated Multicriteria Decision Making Scheme Employing Chinese Environmental Esthetics for Facility Layout Design Evaluation. Journal of Industrial and Production Engineering.

[6] Deb, S.K. 2010.Facilities Layout Planning Based on Fuzzy Multiple Criteria Decision Making Methodology. International Journal of Production Research.

[7] Darmanto, Eko. 2014. Penerapan Metode AHP untuk Menentukan Kualitas Gula Tumbu. Universitas Muria Kudus.

[8] Dweiri, Fikri. 1999. Fuzzy Development of Crisp Activity Relationship Charts for Facilities Layout. Journal of Computers and Industrial Engineering.

[9] Gracia, Alberto Diaz. 2008. Facility Planning and Design. United Stated of America: Pearson.

[10] Purnomo, Hari. 2004. Perencanaan dan Perancangan Fasilitas. Edisi Pertama. Yogyakarta: Graha [11] Ilmu. Saaty, Thomas L. 1993. Pengambilan Keputusan Bagi Para Pemimpin.PT. Pustaka Binaman Pressindo.

[12] Sinulingga, Sukaria. 2009. Perencanaan dan Pengendalian Produksi. Yogyakarta: Graha Ilmu.

[13] Wu, C. R. Chang dan C. W. Lin H.L. 2008.A Fuzzy ANP-Based Approach to Evaluate Medical Organizational Performance.Information and Management Science Volume 19. 